Meta

Journal des traducteurs

Translators' Journal

\title{
Teacher Feedback in Online Education for Trainee Translators
}

\section{Wilhelm Neunzig et Helena Tanqueiro}

Volume 50, numéro 4, décembre 2005

Pour une traductologie proactive - Actes

For a Proactive Translatology — Proceedings

Por una traductología proactiva - Actas

URI : https://id.erudit.org/iderudit/019873ar

DOI : https://doi.org/10.7202/019873ar

Aller au sommaire du numéro

Éditeur(s)

Les Presses de l'Université de Montréal

ISSN

0026-0452 (imprimé)

1492-1421 (numérique)

Découvrir la revue

Citer cet article

Neunzig, W. \& Tanqueiro, H. (2005). Teacher Feedback in Online Education for Trainee Translators. Meta, 50(4). https://doi.org/10.7202/019873ar

\section{Résumé de l'article}

Les auteurs présentent leurs réflexions sur l'importance d'apporter un feed-back individualisé et immédiat dans l'enseignement on-line, c'est-à-dire d'assurer un « dialogue pédagogique » entre l'élève et le professeur, lorsque celui-ci commente les propositions de traduction, donne des pistes, propose des stratégies de solutions, corrige les erreurs individuelles ou aide un élève parce qu'il connaît ses lacunes. Les auteurs ont adapté le programme Proxy qui permet d' " espionner » à partir d'un ordinateur central ce qui se passe dans l'ordinateur de l'élève et ils l'ont combiné à l'application Winpopup, bien connue, qui permet d'envoyer à partir de l'ordinateur du professeur des messages à ceux des élèves. Ils présentent une étude empirico-expérimentale réalisée avec des élèves d'allemand et de portugais qui apporte les premières données sur la l'adéquation des différents paradigmes du feed-back à la formation de traducteurs en ligne et à distance.
Ce document est protégé par la loi sur le droit d'auteur. L'utilisation des services d’Érudit (y compris la reproduction) est assujettie à sa politique d'utilisation que vous pouvez consulter en ligne.

https://apropos.erudit.org/fr/usagers/politique-dutilisation/ 


\title{
Teacher Feedback in Online Education for Trainee Translators
}

\author{
WILHELM NEUNZIG \\ Universitat Autònoma de Barcelona, Barcelona, Spain \\ willy.neunzig@uab.es \\ HELENA TANQUEIRO \\ Universitat Autònoma de Barcelona, Barcelona, Spain \\ Helena-Tanqueiro@uab.es
}

\begin{abstract}
RESUME
Les auteurs présentent leurs réflexions sur l'importance d'apporter un feed-back individualisé et immédiat dans l'enseignement on-line, c'est-à-dire d'assurer un « dialogue pédagogique » entre l'élève et le professeur, lorsque celui-ci commente les propositions de traduction, donne des pistes, propose des stratégies de solutions, corrige les erreurs individuelles ou aide un élève parce qu'il connaît ses lacunes. Les auteurs ont adapté le programme Proxy qui permet d' " espionner » à partir d'un ordinateur central ce qui se passe dans l'ordinateur de l'élève et ils l'ont combiné à l'application Winpopup, bien connue, qui permet d'envoyer à partir de l'ordinateur du professeur des messages à ceux des élèves. Ils présentent une étude empirico-expérimentale réalisée avec des élèves d'allemand et de portugais qui apporte les premières données sur la l'adéquation des différents paradigmes du feed-back à la formation de traducteurs en ligne et à distance.
\end{abstract}

\begin{abstract}
The authors present their views on the importance of providing individual, immediate feedback in on-line teaching. This guarantees "teacher-student dialogue", through which the teacher can provide feedback on student translations, offer prompts and strategies, and correct and support students since they are aware of their individual strengths and weaknesses. The authors have adapted the Proxy program, enabling the teacher to "spy" on the student's computer, and have combined it with the well-known Winpopup application permitting messages to be sent to the students' computer screen. An empirical experiment is described involving students of German and Portuguese, which provides initial data on the appropriateness of different feedback paradigms for on-line and distance education of trainee translators.
\end{abstract}

MOTS-CLÉS/KEYWORDS

teacher feedback, teaching translation, empirical research, translation protocols, online education

\section{Introduction}

University education in Europe is undergoing far-reaching changes as part of what is known as the "Bologna process", which aims to harmonise higher education across Europe, thus facilitating international recognition of university qualifications and student mobility. At the same time, our concept of education is also changing: instead of traditional classroom teaching we are now moving towards a model which combines face-to-face teaching, tutored learning (harnessing the advantages of the Internet) and guided self-study (both individually and in groups), all of which underlie the now oft-mentioned student "portfolios" and subject "activity sheets".

The Internet and e-mail have been in use for some time now in translator education, as means of facilitating teacher-student contact in on-line discussion, video-conferences and distance education courses. We have seen "virtual translation workshops", "on-line translation modules" and more recently on-line Master's and Doctor's degrees, along with Internet-based "task 
learning" programmes. However, the Internet is not yet considered to be an essential or central element of translator training. Perhaps what is missing is the direct classroom contact with the teacher, the "teacher-student dialogue", in which the teacher responds to student translation options, suggests guidelines and strategies for problem solving, corrects student errors and provides support to the individual student based on his or her knowledge of their strengths and weaknesses; in other words, what is missing is immediate or contiguous teacher feedback.

Given the importance of this direct contact and feedback in the teaching process, teachers must make an effort to prepare for the challenge of less personal interaction with students. This may require reconsideration of teaching methodologies. One such approach is to carry out empirical research into the possibilities and advantages offered by distance learning settings. The approach taken should be empirical, since a reflective or introspective approach is inappropriate in the light of the lack of personal experience or similar approaches which might provide guidelines. Nor does it seem viable to simply "copy" or "transpose" the concepts and methods of traditional education into the new media. Rather, we need to develop and optimise the means which will enable us to simulate, at least partially, the interactive element of traditional classroom teaching and thereby ensure personalised teaching and immediate teacher feedback. This can be done by harnessing the advantages of the Internet. This article describes an empirical study designed to evaluate the potential of this technology in distance education for trainee translators. The study was firstly carried out with students translating from their native Spanish or Catalan into their B language (German) and was then replicated with students translating into Portuguese to ensure the extrapolatability of the preliminary results to the translations between such closely related cultures and languages as Spanish and Portuguese.

\section{Referential Framework: Teacher Feedback}

A brief review of the literature (see: Butler \& Winne, 1995 or Jacobs, 2000), reveals two main criteria for teacher feedback which are relevant to our purposes here: firstly, whether the feedback is simple or more elaborate, and secondly, whether the feedback is given immediately after the student's action or at some later stage. "Simple feedback" may comprise an evaluation of the student's contribution (reinforcement-disapproval), informing him or her whether the answer is correct or incorrect, or alternatively it may entail an indication of what the right answer is in the hope that the student will remember it, i.e., what we may term "corrective" or "informative feedback". "Elaborate feedback" with instructive responses may take the form of prompts or guidelines which help the student to find the right answer (the "answer until correct" approach), which we could term "orientative feedback". Alternatively it may comprise an indication of the most appropriate strategy to find an acceptable solution, which we could term "explanatory feedback", or finally by presentation of a possible solution (in this case: a model translation) which the students can compare with their own work, and learn by imitation, autonomously regulating their own learning process.

Regarding when feedback occurs, we would like to introduce here the concept of "feedforward", which we might also refer to as "preventive" or "anticipatory" feedback. These terms may seem contradictory: the words feedback and anticipatory seem to clash with each other. However, this term has been chosen, firstly, to maintain the term "feedback" throughout the various paradigms and, secondly, because with Jakobsen ("Translation problems are easily identified from the distribution of time delays", 1999: 18) we believe that when a typical translation problem occurs, student translators (and indeed professionals too) stop to consider various possible solutions: if after a certain amount of thought they receive a guideline or prompt, then this is anticipatory feedback in the sense that the translation has not yet been formulated in writing. As we shall see, this represents the great advantage of on-line teaching.

\section{The Traducere Navem Program}

Within translation studies interest in empirical research into the translation process underwent a boom in the 1980s with adaptation of "Think Aloud Protocols". Despite the methodological and 
epistemic problems involved, the technique represented a major step forward for observation of the translation process. More recently, empirical research has begun to employ a data collection methodology which we may term "Translation Protocols". This involves using a computer program (for example, Proxy -used by the PACTE group in its 2005 study of translator competence) which allows the researcher to "spy" on the translator's (or student's) computer during the translation process and which records (just like a videotape) all the modifications, time periods (including pauses) and Internet or computer searches carried out. In other words, it records, in a separate file, in real time and invisibly to the translator, all the steps in the process: corrections, document checking, modifications, etc., thereby permitting in-depth analysis of the entire translation process (for further details see Neunzig, 2002).

We have adapted this instrument for distance teaching purposes and have combined it with the well-known Winpopup application which permits the teacher to send messages from his or her computer to the students. This program, which we call Traducere Navem, enables us to: - "spy" on the student while he or she carries out the translation, similar to language laboratory and interpreting room procedures;

- send screen messages to the student's computer. These may involve reinforcement, disapproval, correction, information, suggestions, etc., in other words, teacher feedback;

- to write directly on the student's screen, deactivating the student's mouse, thus showing him or her the solution, as shown in the accompanying graph.

\section{Working Hypothesis}

The lack of a research tradition on the teacher's role in translator training and the absence of work analysing the effect of teacher feedback in translation studies, prevents us from complete concretion of our working hypotheses. Therefore, we take a "What happens if ..." (Gile, 1998:

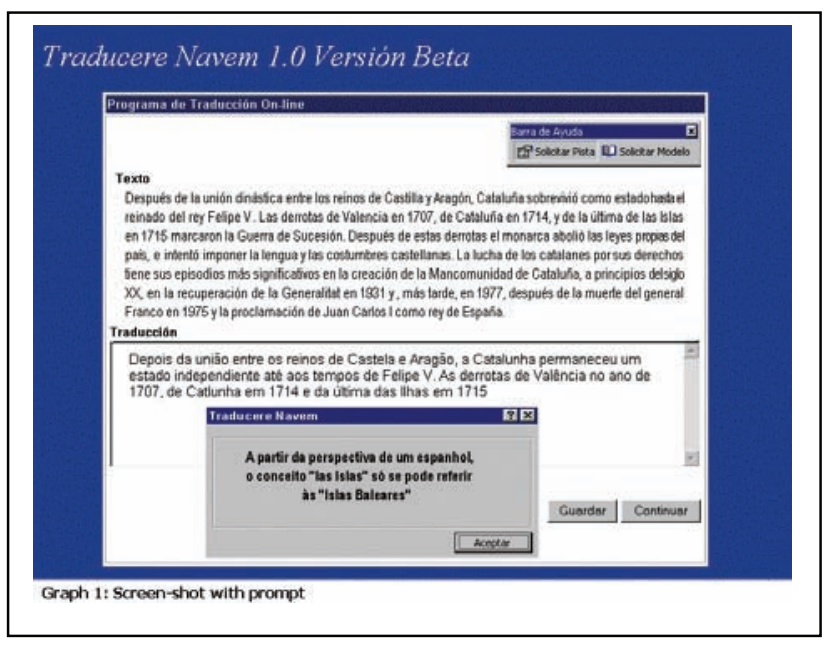

76) experimental approach, in an effort to confirm the following hypotheses:

- It is possible to teach a practical, interactive translation class over the Internet, which students will react to positively;

- The attitude of students to their translation class, the translation process and the final result depends (or at least is partly a consequence of) the type of teacher feedback employed (whether simple or elaborate), how (whether individual or "ready-made") and when it is administered (whether anticipatory, contiguous or follow-up);

- The type of feedback, how and when it is administered has an influence on the student's subjective acceptance of the teaching model;

- The student's attitude to the translation, the process, final outcome and their subjective evaluation of the type of learning model is independent of the two working languages between which translation takes place.

\section{Experimental Design}

\subsection{Experimental Variables}

Definition and implementation of experimental variables is a central problem in designing empirical experiments. This comprises definition of the independent variable (or variables) (i.e., the variables that the researcher can freely adjust in order to observe their effect on the dependent variables), the dependent variables (reflecting the effect of the independent variables) and control and elimination of extraneous variables or confusion, whose influence may distort the results. 


\subsubsection{Independent Variables}

In our experiment, the independent variable is, as may be deduced from the title, teacher feedback: Graph 2 sets out the theoretical possibilities for administration of written feedback in a distance education context. Those of most interest to our present purposes are as follows:

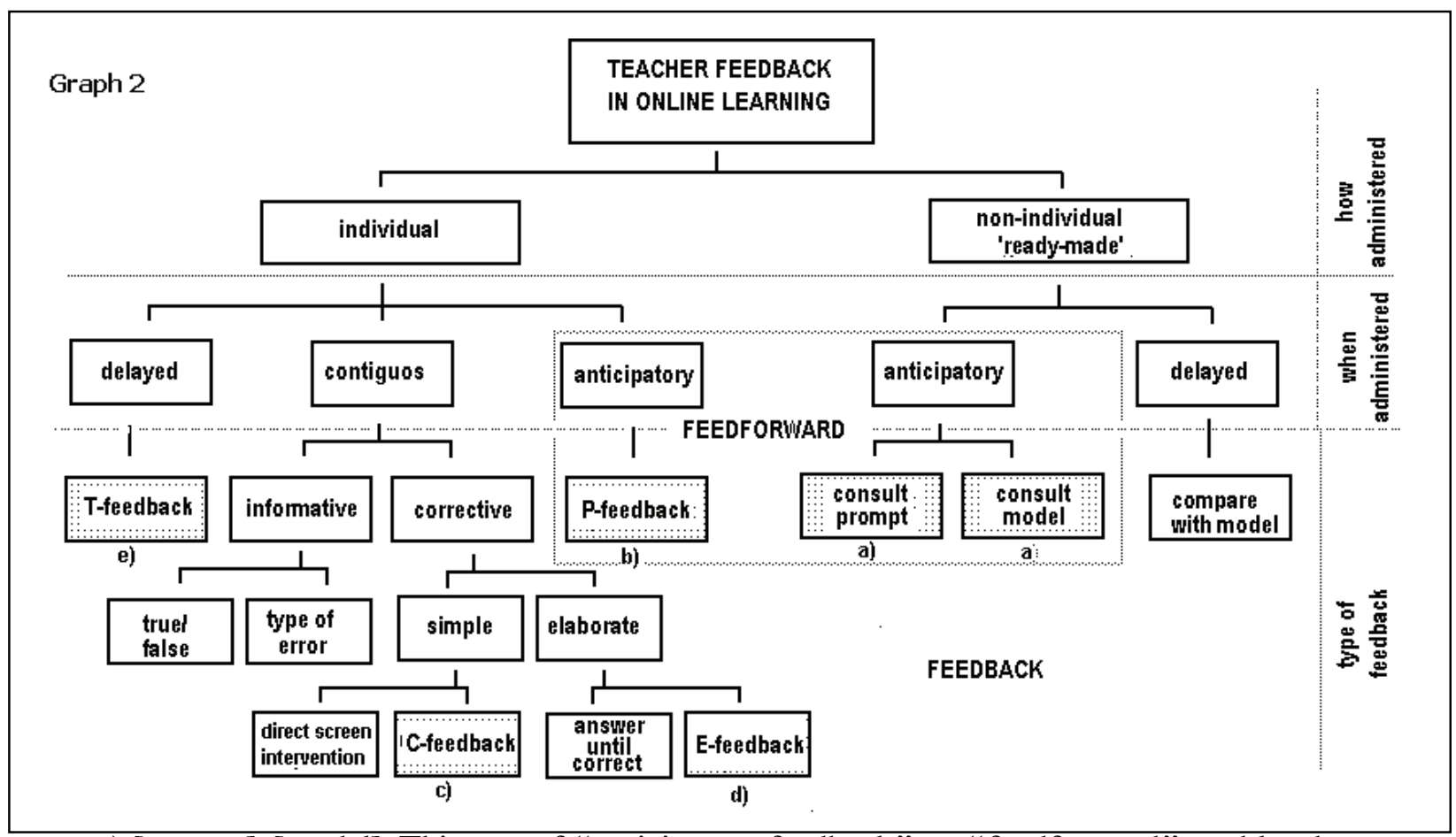

a) [prompt], [model]: This sort of "anticipatory feedback" or "feedforward" enables the student to avail of "prompts" or "translation models" while working;

b) [P-feedback]: Preventive feedback (prompts, comments, help or warnings) administered when students are about to run into a problem, to prevent them from making a mistake;

c) [C-feedback]: in the case of simple corrective feedback, mistakes are corrected as soon as committed, a screen window opens showing the student the errors made;

d) [E-feedback]: Elaborate and orientative feedback provided directly after commission of errors comprise prompts or indications of the most appropriate strategy to be applied to find an acceptable solution;

e) [T-feedback]: Traditional feedback is, undoubtedly, the easiest type of individual feedback to administer in distance teaching: students send their translations by e-mail and the teacher "returns" the corrected version after a period of time.

Based on experimental trials, it was decided to eliminate informative, direct on-screen, "answer until correct" and "direct screen intervention" feedback, since it was found that these tended to confuse rather than help students.

\subsubsection{Dependent Variables}

The dependent variable reflects the action and impact of the action performed (feedback). In this case, the aim was to study the influence of feedback on:

a) subjective student reaction (i.e., approval or disapproval) to the new teaching methodology, under different types of feedback (questionnaire);

b) the immediate reaction as reflected in the student translations on receiving a certain type of feedback 


\subsubsection{Extraneous Variables}

Extraneous variables have an non-desired impact on the dependent variable, which we tried to eliminate by pre-selection of experimental subjects and paired samples. The following controls were performed: for (a) foreign language competence, (b) basic translation competence, (c) subjective comprehension of the source text, (d) comparability of texts to be translated, i.e. that texts were parallel. Steps were also taken to eliminate (e) the influence of the researcher, in this case, the class teacher.

\subsection{Experimental Universe and Groups}

It was decided to perform a "repeated measurement" type of experiment (i.e., involving comparison of data obtained from a single group under various types of feedback) in combination with a "random" trial (comparison of data coming from a number of "parallel" groups, in this case three groups exposed to different feedback), since this design provides a wide basis from which to draw conclusions. When the number of subjects is limited, they cannot be randomly distributed among experimental groups, because there is no guarantee that the confusion variables will be distributed equally among the various groups. It was therefore decided to employ the "paired samples" method, on the basis of student grades in the "B4 language" and "translation into the B language" subjects; i.e., the grades obtained at the end of the first cycle of the degree (thus, also indirectly controlling for the extraneous variables "foreign language competence" and "basic translation competence"). In the case of the students of Portuguese, it was decided to observe a single group ( 9 students) selected on the basis of comparable criteria (grades from "C6 language" and "translation into Portuguese language"), since the feedback paradigms found to be counterproductive in the initial trials with German students were eliminated. The aim was to ensure that groups were also as "parallel" as possible in terms of subjective comprehension of the source text. This was done by means of comprehension questions administered before the beginning of translation work. The result is the experimental design shown in graph 3, in which three experimental groups were observed while translating under different conditions:

a) The three groups began translating the first section of the text under the same feedback conditions: they were given prompts and the possibility of consulting model translations when encountering problems. The results obtained serve to confirm that the groups were "parallel", but also served as a "baseline" for our experiment, i.e., the results obtained on offering this ready-made, easily programmable feedback, were to serve to justify or otherwise the use of more elaborate or individualised types of feedback, which is however, more difficult to administer. This first phase then, served indirectly, as a "control group".

b) The three groups were exposed to different types of feedback during the second section of the translation, i.e.:

- group 1 were provided with simple feedback, a combination of error correction (corrective feedback) and information on the type of error committed (informative feedback);

- group 2 received elaborate feedback containing hints and indications as to the most appropriate strategy for finding an acceptable solution, either by explanatory or preventive feedback;

- group 3 performed the translation under the same feedback conditions as the first section, i.e., they continued to receive hints and could consult models.

c) All three groups translated the third section of the text under identical feedback conditions:

they are asked to finish the translation at home and send it to the teacher by e-mail.

For the Portuguese students, the design set out in graph 4 was employed. 

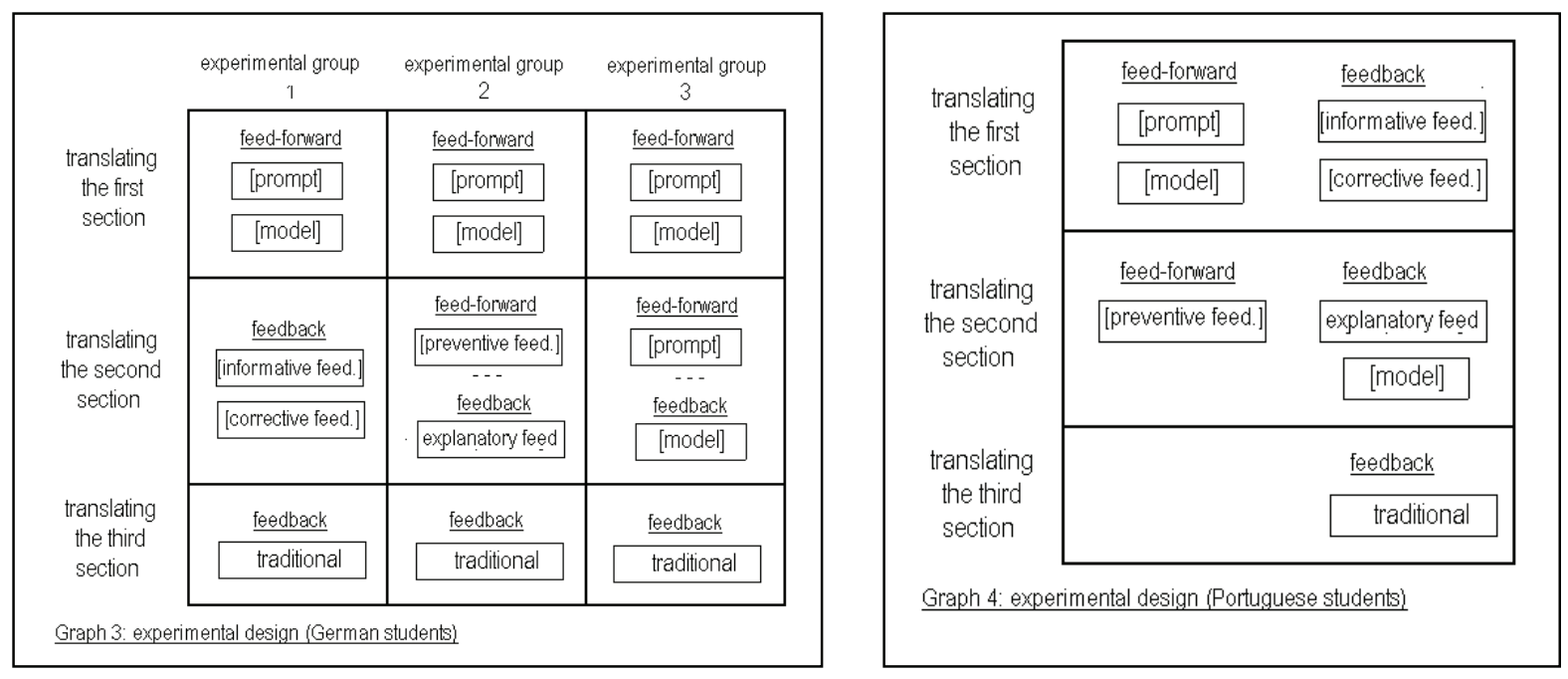

\subsection{Information and Instructions}

It is essential to eliminate the influence of the researcher if results are to provide worthwhile insights, as pointed out by D. Gile (1998: 74) "[...] research in translation and interpreting studies involves participation of the investigator in the process [...], and thus entails the risk of interference by the researcher and/or a significant influence of the research procedure on the phenomena under study." To eliminate this interference, it was decided to use the well-known research ploy in which the experiment was presented to the subjects as designed to study entirely different issues. The instructions given to the students hid the real objective of the study, and led them to believe that their task was to evaluate a self-learning translation program which included "prompts" and "computerbased comments" (the fictitious Traducere Navem program). It was decided to conceal the real objective, since as the students know the teachers, the experiment would be taken as an exam, which would, undoubtedly, have a negative effect on its validity.

It is unlikely that the subjects suspected that this was not the real objective of the experiment, since in the context of the technological advances currently taking place, it is not entirely unfeasible that a self-learning computer-based programme with "intelligent output" should be capable of replacing the teacher in practical class sessions. In addition, the fact that participating students were offered a small fee $(25 €)$, helped to make the "Traducere Navem - self-instructional translation program" ruse more credible. It served to conceal the real purpose of our experiment.

\subsection{The Student's Task}

The subjects were provided with a table and computer running the Traducere Navem "program". Within reach, they had bilingual and monolingual dictionaries, an encyclopaedia and a list of the most frequently used on-line German resources (for the Portuguese group the address of the on-line translation resources page of the Centro Virtual Camões was sufficient). They were also given a page with the text to be translated. On running the Traducere Navem program, an on-screen welcoming message appeared, complete with the program name and a list of credits superimposed over a "Toledo School"

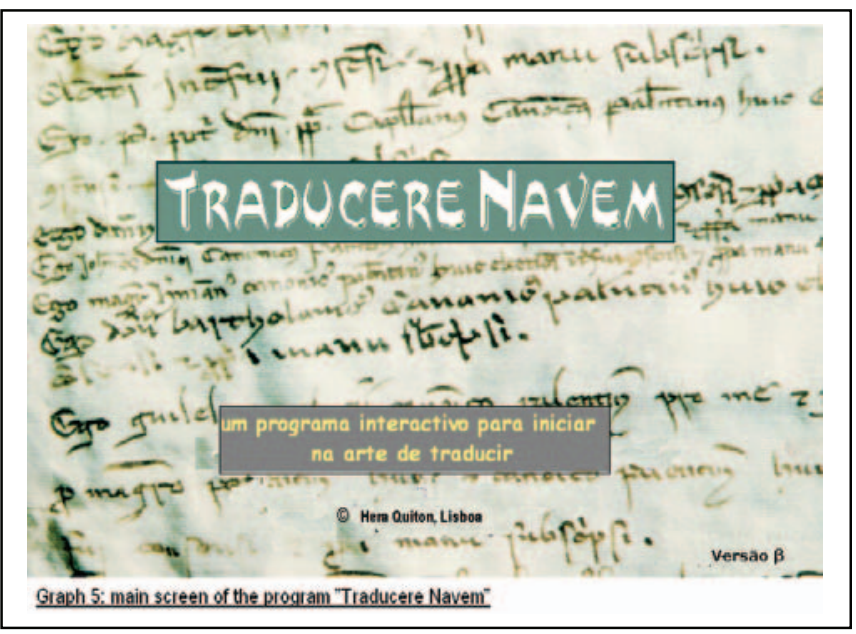


historical manuscript. They were then asked to answer comprehension questions on the text to be translated. The screen (see graph 6) is divided into two sections: the text to be translated appearing in the upper section, the student writing his or her translation in the lower screen. In the right-hand section of the upper screen, a number of icons permit students to ask for "prompts" or a "model text" if they find they cannot make further progress. To give the teacher-researcher time to react to student demands and, also to maintain the impression that what is being tested is an automatic computer program, as soon as students click on these items the following message appears "Your request is being processed, this may take some seconds". During the second phase of the experiment, students are shown a window setting out the errors they have made, i.e. feedback.

\subsection{The Focus of the Study: the Texts to Be Translated}

In a repeated measurement experiment, in which the same subject is observed in different translation situations, comparable texts are required for the various measures. In this case, it was decided to employ a simple but effective approach: rather than seeking out texts which were practically identical or equal for the purposes of the experiment, we employed a single text which was then divided into the required sections. This ensured that the "texts" (i.e., the various sections of a single text) were very similar: they were written by the same author, concerned the same subject matter, employed the same style and register. The text chosen was part of a Catalan Government webpage (www.gencat.es) setting out an introduction to Catalan history.

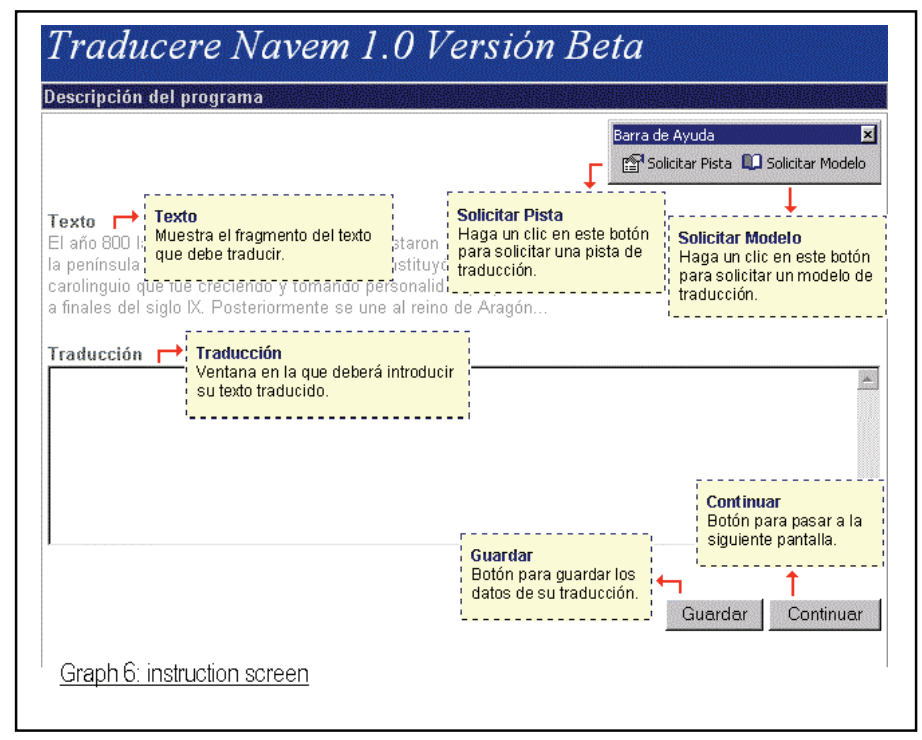

\subsection{Questionnaires}

Questions through the various stages of the experiment are directed at obtaining information on the students' subjective assessment of their experience with the fictitious self-instruction translation program Traducere Navem. These questions are limited in number and take the form of multiple choice items grade according to a more or less ordinal scale. For example, this item on elaborate feedback:

a) Without the comments/corrections provided by the program I don't think I could have done an acceptable translation of this section of the text.

b) The answers/comments provided by the computer helped me to think about and correct my errors.

c) Some of the prompts/corrections helped me to improve my translation, but many of them seemed unnecessary.

d) The prompts/comments and correction interrupt the translation work and hinder concentration.

\section{Results}

Comparative analysis of the results concerning the different types of feedback with students of German and Portuguese enables us to conclude as follows: firstly, elaborate feedback, whatever the means of presentation, appears to be more effective than the other forms of on-line teacher intervention, not only because the students prefer it to simple feedback, to provision of translation models and traditional feedback, (although five students, [3 in German, 2 in Portuguese] would prefer to discuss their translation problems in a face-to-face classroom setting rather than via distance learning); it is also the most widely accepted form of feedback, and has most influence in 
terms of modification of translator behaviour (the students tend to incorporate the suggestions and hints into their translation) and gives rise to the best translations (in $85 \%$ of cases the feedback led to acceptable translations). Preventive provision of prompts however, seems to be more appropriate than explanations offered after an error has been committed: there is little point knowing that a student is going to commit an error and then waiting for this to happen in order to correct it; it would seem much more logical to take advantage of the medium's strong points and act to prevent the error. It was also observed that the students, when correcting errors as a result of a post-error explanation, tended to commit other errors, for example, in cohesion, genre, collocation, grammar, etc., which do not seem to occur when the prompt is given beforehand. Nevertheless, the explanatory intervention is not appropriate in the case of grammar problems: on-line translation teaching is not the setting for lengthy explanations of points of grammar, since this tends to have a negative, interruptive effect on the translation process.

Simple feedback does seem in line with student expectations in the case of grammatical errors (at least for those students who actively correct their errors) and would appear to confirm some of the results referred to previously (grammatical errors are not directly linked to shortcomings in declarative knowledge). Acceptance of simple corrective feedback, which is undoubtedly necessary for correction purposes, at least when rules of use are infringed, is however less than uniform. In this respect, a distinction can be drawn between two types of students: those who find contiguous correction a source of distraction which interrupts the translation process and others, who find it a source of security, and prefer to correct their mistakes while working. In on-line teaching, after some time teachers get to know their students' preferences and can provide feedback accordingly. In any case, contiguous administration of corrective feedback is seen as superior to follow-up feedback, especially among the students of Portuguese.

Surprisingly, the "translation model", no matter how administered, is less successful than all the other forms of intervention and even proved counterproductive, at least when students do not feel they are being observed: very few students used the model as a guideline, instead they tend to simply copy and modify it, committing serious errors (especially the German students). Some even directly cut and pasted the text without modifying (or possibly even reading) it. However, when the model is offered as feedback, $40 \%$ of students used it in order to make the appropriate corrections to their translation (especially, the Portuguese group), although the majority either ignored the model or still make serious errors on "correcting" their work. It would appear then that "translation models" do not appear to be an appropriate component of such distance learning methodologies; however, these results cannot be extrapolated for all types of text.

Unsurprisingly, simple informative feedback does not lead to satisfactory results. Providing information and discussing the type of error committed by a student is undoubtedly beneficial in a face-to-face situation, facilitating class participation and enabling students to correct each other's work, yet is hardly appropriate for individual learning. The experiment described in this paper does not offer reliable data regarding traditional feedback, i.e., returning corrected student work after a period of time; however, in the subjective assessment only one student expressed a preference for this traditional form rather than contiguous feedback.

Finally, it is interesting to note that the students seem to gradually develop greater confidence in the system, finding themselves more and more at ease with the interventions, a indication of their acceptance of the medium. This is confirmed in the subjective assessment: the students felt that they had not wasted their time and that such exercises are beneficial (for detailed information on this experiment carried out with students of German, see Neunzig, 2001).

\section{Summary}

In planning this experiment, an effort was made to control for the main confusion variables via careful preselection of subjects and paired samples. Division of a single text into several segments, thus obtaining several "parallel texts" was a successful and surprisingly simple strategy. It eliminated the need to turn to "external experts" whose views may often differ from one another. The fictitious Traducere Navem "self-learning translation program" successfully "disguised" the 
real objective of the study and, thereby, served to control the influence of the researcher and the experimental setting.

The Proxy and Winpopup applications enable teachers to intervene preventively and, also to provide comments, corrections and suggestions immediately after the student has made his or her first translation draft of a given sentence or section. The main advantage of this approach is that it enables individual contiguous feedback, which students view positively; in other words, it enables us to simulate, at least partially, a traditional face-to-face translation class, through distance learning media, thus confirming our initial hypothesis. The results also confirm our second hypothesis, under which the translation process and final outcome depend (or at least are partially the consequence of) the type of teacher feedback employed (whether simple or elaborate), how administered (whether individual or "ready-made") and when presented (anticipatory, contiguous or follow-up) and independently of the language pair involved, this last point seeming to support the fourth of our hypotheses. While certain supportive trends were observed, there is not sufficient evidence to confirm our third hypothesis whereby the degree of student acceptance of the teaching methodology is closely linked to the type of teacher feedback and how and when it is administered.

This short study can only seek to make a contribution to the ongoing discussion of on-line translation teaching and aims to promote further work endeavouring to improve and ensure the effectiveness of the approach.

\section{REFERENCES}

Butler, D. and P. Winne (1995): "Feedback and Self-Regulated Learning: A Theoretical Synthesis", Review of Educational Research 65-3, p. 245-281.

Gile, D. (1998): “Observational Studies and Experimental Studies in the Investigation of Conference Interpreting”, Target 10-1, p. 69-93. JACOBS, B. (2001): "Feedback-Paradigmen”, checked on 2 February $2002<$ http://www.phil.unisb.de/ jakobs/wwwartikel/feedback/index.htm>.

JakobSEn, A. L. (1999): "Logging Target Text Production with Translog", in Hansen, G. (ed.): Probing the Process in Translation: Methods and Results, Copenhagen, Copenhagen Studies in Language 24, p. 9-20.

NEUNZIG, W. (2001): "La intervención pedagógica en la enseñanza de la traducción on-line", <http://www.tdx.cesca.es/TDX-1222103-155137/>.

Neunzig, W. (2003): "Estudios empíricos en traducción: apuntes metodológicos”, in Alves, F. (ed.): Cadernos de Tradução: O processo de Tradução 10, p. 75-96.

NeunZIG, W. (2004): “Cómo formar al alunm@ sin verle la cara o Tecnologías de la información en la enseñanza de la traducción a distancia”, Papers de Tradumática, <http://www.fti.uab.es/tradumatica/papers/>.

PACTE (2005): "Investigating Translation Competence: Conceptual and Methodological Issues", Meta 50-2, p. 609620 . 